\title{
Alcohol abuse
}

\section{The problem has not gone away, although the campaigning almost has}

While the alcohol industry sponsors car rallies and advertises beautiful people enjoying drinks in the Caribbean the campaign against alcohol abuse has gone flat. Campaigning against alcohol abuse is neither glamorous nor popular with governments. Any progress towards a political solution to the problem, called for by three medical colleges in 1986 and 1987, seems slight. ${ }^{1-3}$

Alcohol costs money and lives. The annual costs to Britain of road traffic accidents, drink related court cases, days off work, and medical and psychiatric care are estimated at $£ 2$ billion. ${ }^{+}$The excess mortality from alcohol is put at 28000 a year. ${ }^{5}$ Four years ago at least four groups campaigned vociferously against alcohol. The government withdrew funding from most of them in 1987. In 1989 Action on Alcohol Abuse - a group set up by the royal colleges that campaigned particularly vigorously for higher taxation on alcohol, random breath testing, and controls on advertising disbanded because of lack of funds. A ministerial committee set up to deal with alcohol problems under the chairmanship of John Wakeham promised much but never delivered. Converted to a cabinet committee, it has now become far more secretive. Alcohol Concern, the sole remaining recipient of government funding, now faces the might of the drinks trade almost alone.

In the same year that Action on Alcohol Abuse disbanded, the drinks industry set up the Portman group, with $£ 3 m$ to fund research. Alcohol campaigners are concerned that research backed by the drinks industry cannot be unbiasedfor example, in response to the problem of disorder after closing time the group suggested relaxing the licensing laws. ${ }^{6}$

Campaigners against alcohol abuse have had to work hard to avoid being "killjoys." The antismoking lobby can arm itself with the knowledge that any smoking is bad for health. This is not an option open to campaigners against alcohol abuse. For the public, alcohol problems mean cirrhosis and severe psychiatric disorders rather than marital discord, crime, and unemployment, and they do not want their freedom to drink controlled because of the heavy consumption of the few.

Many bodies - including the World Health Organisation and the three royal medical colleges-have accepted the evidence that the amount of damage from alcohol in a community correlates closely with the amount consumed by that community. The most effective way to reduce alcohol consumption is to raise the price. Reducing the harm associated with alcohol is thus more a job for politicians than health professionals. The concern that price increases would not touch "addicts" was refuted by the Lothian study, which showed that an increase in price led heavy drinkers to reduce their consumption as much as light drinkers. ${ }^{7}$

The government has been reluctant to recognise that it has more power than any other group to reduce Britain's alcohol problems. A 1981 Department of Health and Social Security document entitled "Drinking sensibly" recognised that controlling the production, distribution, and price of alcohol would influence consumption, but the government refused to do so because such measures would affect jobs, exports, and government revenue. ${ }^{8}$ The document emphasised that "Government alone cannot secure responsible attitudes towards health matters in the community." This contradicted a report by the Central Policy Review Staff - a government think tank - two years earlier, which argued that "alcohol duties are the single most important instrument the government has for influencing consumption."

At least 15 government departments have alcohol interests. Many are more concerned with increasing consumption than curtailing it. When the Chancellor of the Exchequer raised duty on alcoholic drinks in line with inflation in this year's budget he did not suggest it was for the good of the nation. (Only the increase in cigarette taxation was justified as being a health tax.)

The government fails to act because the drinks industry is such a powerful ally. Not only does the industry give generously to political funds, but many MPs are consultants to alcohol companies and advertising agencies that depend heavily on promoting drink. When the Monopolies and Mergers Commission investigated claims that six breweries owned most public houses and were overcharging for soft drinks and low alcohol beers it recommended that no brewery should own more than 2000 public houses. The brewers were outraged, and the government watered down the committee's proposals, ruling that breweries can keep more than the original 2000 tied houses. Similarly, when the amendment to introduce random breath testing was debated recently, the government refused its MPs a free vote and the motion was defeated. This is despite overwhelming public support for this policy. ${ }^{9}$

The most immediate threat to the level of alcohol consumption will come from the European Community. Britain is committed to the harmonisation of duty within the single market next year, which will mean a fall in the retail prices of most alcoholic beverages in this country. The 
Institute for Fiscal Studies estimates that this will result in a $46 \%$ increase in the volume of alcohol drunk in each household. ${ }^{+}$As a participant in the WHO Health for All by the Year 2000 project Britain is also committed to make "significant decreases in health damaging behaviour such as the use of alcohol." At the moment these two commitments seem irreconcilable.

What is needed is an energetic political campaign on alcohol problems. At the centre should be an organisation equivalent to $\mathrm{ASH}$, which has campaigned so successfully against smoking. It will need active support from organisations like the BMA and other professional associations. The ministerial committee should be resuscitated and given objectives and teeth. If the government is serious about setting targets to improve the nation's health its forthcoming green paper should include plans to reduce alcohol consumption. A united front is needed. Half hearted attempts at tackling the problem of alcohol abuse will get nowhere.

Editorial registrar, $B M \mathcal{F}$

LUISA DILLNER

Royal College of Physicians. The medical consequences of alcohol abuse: a great and growing evil. London: Tavistock, 1987.

Special Committee of the Royal College of Psychiatrists. Alcohol: our favourite drug. London Tavistock, 1986

3 Roval College of General Practitioners. Alcohol: a balanced view. London: RCGP, 1986

4 Robinson D, Maynard A, Chester R. Controlling legal addictions. London: The Eugenics Society, 1989.

5 Anderson P. Excess mortality associated with alcohol consumption. BMJ 1988;297:824-6. 6 Alcohol Concern. Warning: alcohol can damage your health. London: Alcohol Concern, 1991.

Kendell RE, Roumanie $M$, Ritson EB. Influence of an increase in excise duty on alcohol consumption and its adverse effects. BMF 1983;287:809-11.

Bunton R. Changes in the control of alcohol misuse. Br f Addiction 1990;85:605-15.

9 Gloag D. Random breath testing now. BMF 1991;302:403.

\section{Snoring}

\section{Tackle obesity, smoking, and alcohol consumption first}

The recent International Classification of Sleep Disorders defines snoring as loud upper airway breathing, without apnoea or hypoventilation, caused by vibration of the pharyngeal tissues. ${ }^{1}$ Divided into mild, moderate, and severe on the basis of frequency, body position, and disturbance to others, snoring presents considerable problems for epidemiological studies as so much of its evaluation depends on the reports of others. Without a spouse, "bed partner," or light sleeping neighbour snorers may be unaware of any problem. Interviewing partners increases the reported prevalence of snoring, ${ }^{2}$ but their estimates of loudness and duration may be unreliable. More sophisticated monitoring is needed for these and to exclude apnoea and hypoventilation. The prevalence of occasional snoring over the age of 50 may be as high as $80 \%$ whereas the prevalence of habitual or frequent snoring is nearer $30 \%$.

In children snoring has been linked to rhinitis, cough, sputum, and to parental smoking. ${ }^{+}$In adults associations have been found between snoring and ischaemic heart disease and strokes. ${ }^{5 \cdot 7}$ Obesity and cigarette smoking increase the likelihood of snoring, ${ }^{8}$ and these links complicate any assessment of the association with vascular disease. Alcohol consumption has been less clearly associated with snoring, ${ }^{89}$ although most partners are adamant that alcohol increases its frequency and volume. After adjusting for these confounding factors several recent studies have found that hypertension is not significantly associated with snoring. ${ }^{29}$ In a large group of snorers in Toronto referred for assessment of snoring and possible sleep disordered breathing the data were analysed by multiple regression. ${ }^{10}$ Diastolic blood pressure correlated with body mass index, apnoea-hypopnoea index, and nocturnal oxygen saturation but not with an index of snoring. In one study the link between snoring and vascular disease remained after allowance was made for many of these factors. ${ }^{\top}$ Adjustment, however, may be difficult. Abdominal and neck obesity seem more important than general obesity in vascular disease ${ }^{11}$ and sleep apnoea, ${ }^{12}$ but the adjustments for obesity have generally been madëon overall body mass index. Nocturnal assessments of oxygen saturation and breathing have not been part of these epidemiological studies. Although further prospective studies are needed, the relation between snoring and cardiovascular and cerebrovascular disease seems likely to survive adjustments for smoking and alcohol.

This leaves the important question of what part obstructive sleep apnoea plays in the links between snoring and vascular disease. ${ }^{13}$ Patients with obstructive sleep apnoea almost invariably snore, and abnormalities in pharyngeal shape seem similar in snorers and those with obstructive sleep apnoea. ${ }^{14}$ The typically obstructive pattern of silence followed by explosive reopening of the upper airway may be clearly described by a partner. Daytime sleepiness is prominent with obstructive sleep apnoea but is also found in snorers. The prevalence of sleep apnoea (when defined as a sleep apnoea index above 10 an hour) is probably $1 \%$ or more in adult men. ${ }^{15}{ }^{16}$ Disagreement exists over its prognosis, ${ }^{17}$ but it seems clear that, untreated, sleep apnoea carries an increased mortality, particularly in older patients with an apnoea index score above 20 an hour. ${ }^{18}{ }^{19}$ Mortality in these retrospective series was $11 \%$ to $13 \%$ over five years.

A recent study examined 101 men after myocardial infarction, ${ }^{20}$ when some cardiac failure may have led to central apnoea and sleep disturbance. ${ }^{21}$ More obstructive apnoea was found in snorers than in age matched controls, however, suggesting that sleep apnoea, even if mild and undiagnosed, may predispose to myocardial infarction. Some doubts remain as sleep was not confirmed by electroencephalography and controls spent only one night in hospital. Deciding whether the association between snoring and vascular disease depends on obstructive sleep apnoea will require more detailed studies.

In managing these patients obesity, smoking, and alcohol consumption should be tackled first as they increase the likelihood of snoring. If these interventions do not work then relieving any nasal obstruction may help. After these interventions three treatments remain for snoring and obstructive sleep apnoea. Tracheostomy reduces the morbidity and mortality from obstructive sleep apnoea but with considerable inconvenience and morbidity. Uvulopalatopharyngoplasty usually reduces or eliminates snoring but is less successful in obstructive sleep apnoea and has not been shown to reduce mortality. By contrast, nasal continuous positive airway pressure is successful in treating obstructive sleep apnoea and reduces the mortality from vascular complications. ${ }^{18}$ Snoring can also be eliminated, but the inconvenience of wearing a mask all night is unlikely to appeal to snorers, who do not gain the benefit of relief of marked daytime sleepiness.

The present evidence suggests that for simple snoring without obstructive sleep apnoea aggressive treatment is not 